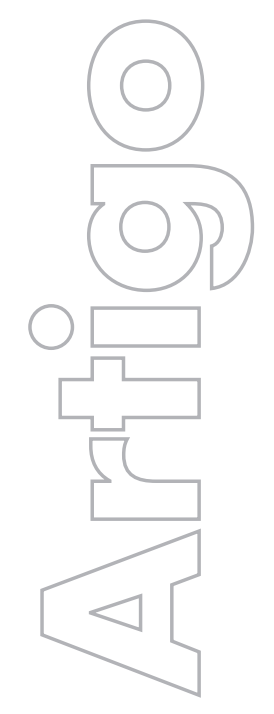

\title{
Ante las imágenes: los desafíos del giro visual para la geografía
}

\author{
Verónica Carolina Hollman \\ UBA
}

\section{revista}

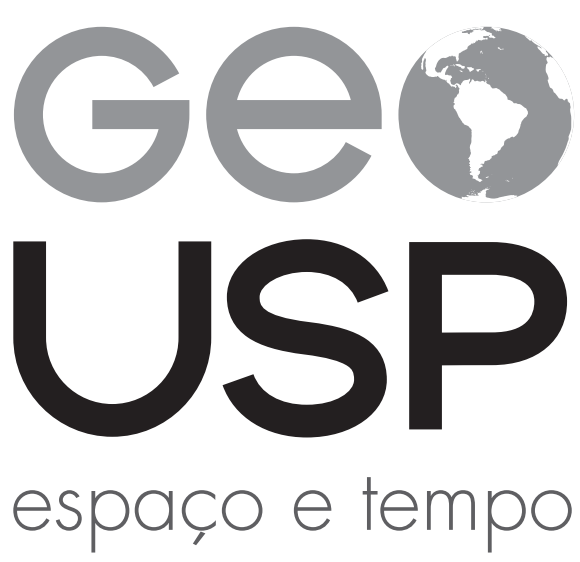

Volume $20 \cdot n^{\circ} 3(2016)$
Como citar este artigo:

LHOLLMAN, V. C. Ante las imágenes: los desafíos del giro visual para la geografía. Geousp - Espaço e Tempo (Online), v. 20, n. 3, p. 518-535, mês. 2016. ISSN 2179-0892.

Disponível em: <http://www.revistas.usp.br/geousp/issue/ view/6465>. doi: http://dx.doi.org/10.11606/issn.2179-0892. geousp.2014.84539.

\section{(c) $(1) \Theta$}

Este artigo está licenciado sob a Creative Commons Attribution 4.0 License. 


\section{Ante las imágenes: los desafíos del giro visual para la geografía}

\section{Resumen}

La visión ha sido concebida como la vía de acceso privilegiada al conocimiento en la geografía. Proponemos revisar la literatura que, desde algunos sub-campos disciplinares, ha problematizado la disciplina como un discurso visual del mundo. Buscamos identificar y analizar una serie de interrogantes que abre este giro visual para la geografía en torno a las estrategias más apropiadas para aproximarnos, por un lado, al análisis de las imágenes desde su propio código visual y complejidad; por otro, a los modos de mirar producidos y puestos en circulación desde la disciplina y sobre todo, a su impacto en la configuración de memorias e imaginarios geográficos.

Palabras clave: Giro visual. Imágenes. Mirada. Geografía. Método.

\section{Ante as imagens: desafios do giro visual na geografia}

\section{Resumo}

A geografia tem entendido a visão como a via de acesso ao conhecimento. No entanto, esta confiança na visão e nas imagens começou ser questionada em diversos sub-campos da disciplina que a problematizaram como um discurso visual do mundo. Propomos revisitar os trabalhos que têm colocado as imagens sob questão e analisado as relações entre visão, poder e conhecimento geográfico. Procuraremos identificar algumas das perguntas que apresenta esta virada visual para a disciplina com atenção às estratégias apropriadas para nos aproximarmos à análise das imagens no seu código visual e na sua complexidade, dos modos de olhá-las e ao seu impacto na configuração de memórias e imaginários geográficos.

Palavras-chave: Virada visual. Imagens. Olhar. Geografia. Método.

\section{Facing with images: challenges opened by the visual turn to Geography}

\section{Abstract}

Whether as field observation or through images, vision has been conceived by Geography as the access to knowledge. However, the trust placed in vision and images has recently been unpacked by both looking at the discipline as a 
visual discourse and analyzing the relation among vision, power and geographical knowledge. The aim of this paper is to identify some of the challenges that the visual turn puts forward to Geography regarding the study of both images and the ways of seeing in its complexity as well as their impact on our geographical memory and imaginations.

Keywords: Visual turn. Images. Ways of seeing. Geography. Visual methods.

\section{Ante las imágenes: los desafíos del giro visual para la geografía}

"Tus ojos te distraen. Si los cierras, aprenderás mejor", explica Khorshid, el pequeño protagonista de la película Le silence, a dos niñas, compañeras ocasionales en el trayecto desde su casa al trabajo. Khorshid es ciego y tiene una audición finísima que entrena rigurosamente cada día identificando las sutiles diferencias en los sonidos que emiten las abejas. Ya ha aprendido que el sentido que le permite entablar una relación con el mundo también lo distrae y desvía en sus desplazamientos cotidianos. A pesar de las indicaciones de su madre y amigas, Khorshid suele librarse de los tapones auditivos que utiliza en cada desplazamiento e ineludiblemente una bella melodía o una voz delicada y melódica, lo invita a cambiar de itinerario. Así, en un inmenso y concurrido mercado, Khorshid sigue una melodía y su amiga Nadareh lo pierde de vista. El plano picado que elige el director en esta escena muestra con efectividad que la tarea de encontrarlo "con los ojos" resultará imposible. Nadareh resuelve cerrar sus ojos y permitir que su sentido auditivo la oriente hasta encontrar la melodía que sedujo a su amigo. El recorrido de la cámara nos permite descubrir los detalles que la niña comienza a percibir desde el preciso momento que renuncia al acto de mirar (Le silence, 1998).

Sin agotar aquí todo lo que esta bellísima película con guión y dirección de Mhoser Makhamalbf puede suscitar, las dos escenas relatadas resultan estimulantes para revisar la relación de la visión y las imágenes con la geografía, en tanto campo de conocimiento. El reconocimiento analítico de las imágenes y de los modos de mirarlas, denominado visual turn o pictorial turn, atañe a otras disciplinas del campo de las Ciencias Sociales. Sin embargo, en la geografía toma una particularidad: se trata de una disciplina, como señala Thomas Conley, con una tradición en el uso de las imágenes como fuente de conocimiento (Dikovitskaya, 2006, p. 127). Este giro no niega ni rechaza esa tradición visual, sino que propone revisarla para desmontar la transparencia y la autoridad atribuida a las imágenes.

En un artículo publicado en 1979, Yi-Fu Tuan ya discutía el lugar de la visión en la geografía al afirmar que la ceguera hacía virtualmente imposible el desarrollo de la carrera geográfica, en cambio no constituía obstáculo alguno para la sabiduría (1979, p. 413). Si a principios del siglo XX Halford Mackinder la definió como una "forma de visualización" 
(Ryan, 2004), un siglo más tarde ha sido descrita como una disciplina que "trabaja el poder comparativo de la visión" (Matless, 2003, p. 222). Esta continuidad evidencia la matriz visual de la disciplina en su aproximación al estudio del espacio y territorio. En efecto, la visión ha sido concebida sistemáticamente como la vía de acceso privilegiada al conocimiento (Pocock, 1981). El recurrente uso de diversas tecnologías de visualización en su enseñanza afirma los vínculos existentes entre la visión y el conocimiento geográfico. Todavía más: el entrenamiento de la visión se asumió como una tarea propia de la geografía, imprescindible como parte de la formación básica pero también para desarrollar cada una de las prácticas del campo disciplinar. El itinerario de este artículo se inicia explorando algunos trabajos que, al igual que la niña de la película Le silence, se han permitido "cerrar los ojos" y desconfiar, al menos transitoriamente, de la visión. En las siguientes secciones, se identifican y analizan algunos de los campos problemáticos que presenta el giro visual para la disciplina.

\section{Un giro que problematiza la matriz visual de la disciplina}

El giro visual, como ya ha ocurrido con otros giros que movilizaron el pensamiento geográfico, ha provocado cierta incertidumbre e inquietud. Probablemente resulte paradójico adscribir tal giro a una disciplina que, como ya hemos apuntado, ha privilegiado la visión como vía de acceso al conocimiento. Sin embargo, esta matriz visual no había implicado la conformación de "un campo del saber geográfico explícitamente referido a las imágenes y a la imaginación” (Lindón; Hiernaux, 2012, p. 10). La referencia a una serie de artículos publicados en el año 2003 en la revista anglosajona Antipode resulta ineludible, incluso admitiendo que datar el inicio de un movimiento intelectual es una tarea un tanto arbitraria. Tal vez, estos artículos dieron visibilidad a un conjunto de investigaciones que ya venían examinando la relación entre visión y conocimiento geográfico, particularmente desde los sub-campos disciplinares de la geografía cultural y la geografía histórica así como la historia de la cartografía, un campo autónomo pero próximo a la geografía.

Gillian Rose abría aquel número de Antipode con un artículo tan breve como provocador sosteniendo que la profusa utilización de imágenes en la producción del conocimiento geográfico no había sido acompañada de una reflexión sistemática sobre lo visual en las prácticas disciplinares de los últimos dos siglos. Su argumentación se centraba en las jerarquías producidas y reproducidas en la proyección de imágenes, una práctica recurrente en conferencias y clases de geografía. El artículo de Rose funcionó como una efectiva provocación intelectual en torno a la condición visual de la disciplina como lo demuestra la serie de ensayos de autoría de Félix Driver, James Ryan, Mike Crang y David Matless, publicados en el mismo número de la revista ya citada. Más allá de los aspectos que suscitaron mayor controversia, todos los ensayos coinciden en señalar el giro visual como una oportunidad para tomar posición ante las imágenes y discutir el tipo de competencias que supone contemporáneamente la educación visual en la formación profesional de un geógrafo (Crang, M., 2003; Ryan, 2003; Thornes, 2004). 
Las investigaciones centradas en la enseñanza, acaso la práctica disciplinar que utiliza con mayor recurrencia las imágenes en diferentes dispositivos de visualización, tomaron cierta delantera. Lejos de indagar las virtudes o los problemas didácticos del uso de las imágenes, temática transitada desde la didáctica de la geografía, el eje de discusión pasó a ser la relación entre la visión, la construcción y la difusión del conocimiento geográfico. Este campo de investigaciones ha demostrado que las imágenes exceden ampliamente la función ilustrativa: ellas ofrecen un modo de mirar, entender y ordenar el espacio geográfico. Así, las investigaciones de Teresa Ploszajska (1999) y James Ryan (2004) sobre la geografía escolar en la Gran Bretaña de fines del siglo XIX y de la primera mitad del siglo $\mathrm{XX}$, apuntan que las imágenes, en formatos tan diversos como los juegos de diapositivas de vidrio, las tarjetas postales para uso educativo producidas por el Imperial Institute y en soportes como los libros escolares y las paredes de los salones de clase (Ploszajska, 1999), estructuraron un discurso escolar geográfico con una mirada imperialista del mundo. Se cuestiona, entonces, la concepción de las imágenes como espejos de lo real y la participación de la geografía en la formación de un conjunto de destrezas en las que se pone en juego la visión, entendido con frecuencia como un entrenamiento estrictamente técnico. Sin embargo, en esta transmisión de reglas que delinea aquello que se incluye (o excluye) del campo de lo visible y sobre todo al convencernos de que ver es sinónimo "de tener y conocer ese real ante nosotros" (Oliveira Jr., 2009), la geografía interviene en la conformación de subjetividades y sensibilidades.

La tarea asumida por la geografía escolar de enseñar aquello que es digno de ser mirado revela que mirar también es un acto que se aprende y por consiguiente está atravesado por condiciones históricas, sociales y espaciales. La doble página de un libro de geografía de principios de siglo XX (Figura 1) brinda algunas claves para reconstruir algunos modos de entrenamiento de la mirada. El Panorama geográfico (izquierda) presenta una serie de ejercicios que figuran al pie de la página: cada elemento de la ilustración es enunciado desde el texto de modo tal que los alumnos/lectores establezcan la relación entre el concepto y los elementos visuales de la ilustración. El texto busca recrear la mirada exploratoria de los dos observadores situados en la imagen en un punto privilegiado de observación. Luego de la explicación de orden conceptual, la serie de dípticos (página derecha) ofrece dos modos de ver (y representar) distintos elementos/accidentes geográficos: la vista, que simula cómo se vería con los propios ojos y el mapa, con una visión cenital. Este esfuerzo por guiar la mirada se extiende a la utilización de otras imágenes y tecnologías de la visión. Por ejemplo, los juegos de diapositivas, utilizados en las proyecciones escolares entre finales del siglo XIX y mediados del siglo XX, solían estar acompañados por un breve texto que homogeneizaba un modo y un ritmo de mirar con la finalidad de eludir las eventuales distracciones de los alumnos y las posibles improvisaciones de los docentes (Hollman, 2016). 


\section{Figura 1 - Ejercicios para entrenar la mirada: ¿Qué y cómo mirar?}

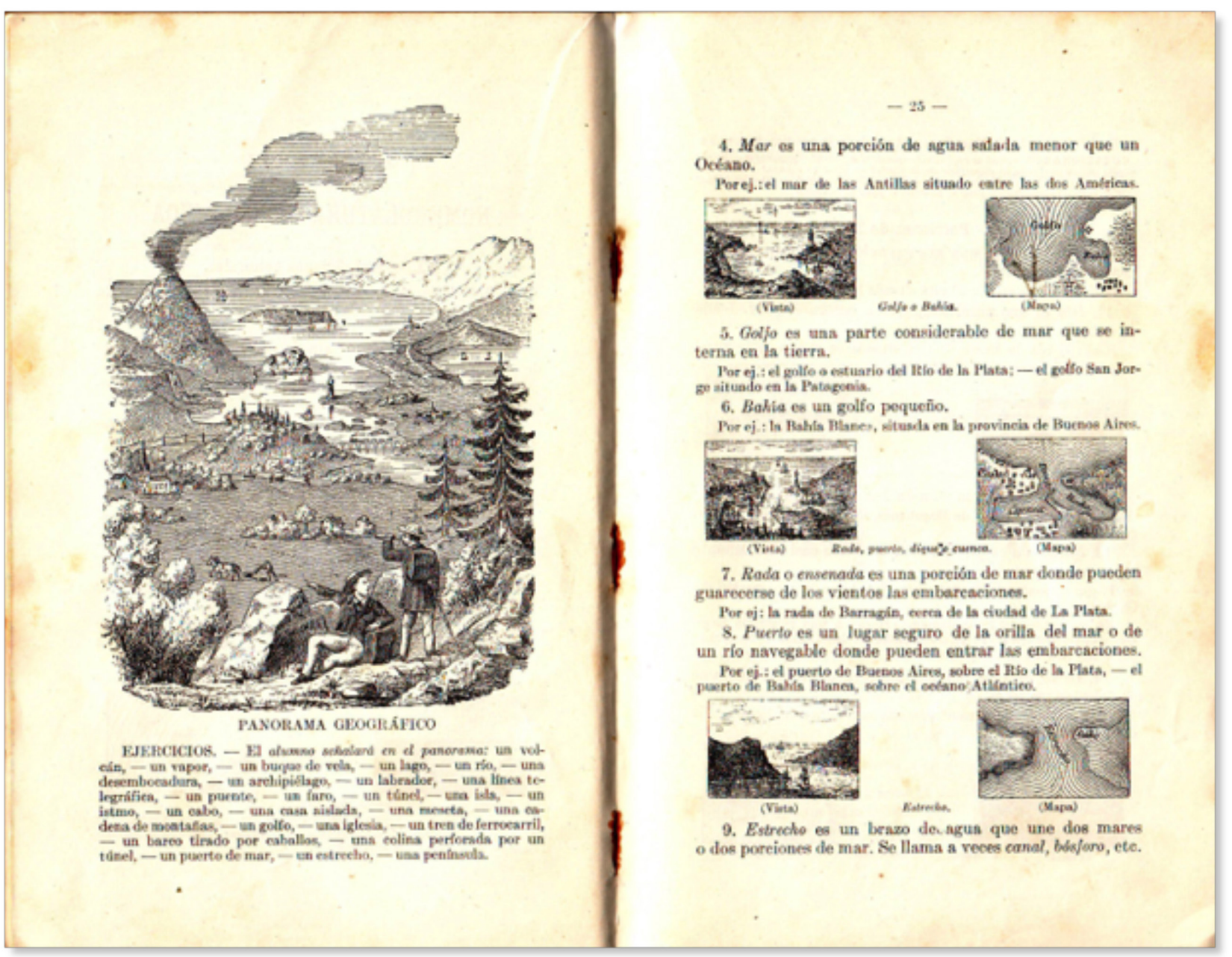

fuente: Hermanos [...] ([1910?], p. 24-25).

Este entrenamiento visual no se ha ceñido a la geografía escolar. En efecto, las imágenes geográficas circulan en otros contextos que exceden ampliamente la institución escolar (Schulten, 2002; Brückner, 2006). Los espectáculos visuales de fines del siglo XIX y principios del siglo XX - los shows de diapositivas de vidrio, los panoramas o las Exposiciones Universales - y más recientemente, los medios de comunicación (Novaes, 2005; Hawkins, 2010) son paradigmáticos de la exposición de universos visuales ante audiencias amplias y no especializadas. Los modos de mirar estas imágenes en cada contexto y lo que ellas evocan, rememoran o disparan, todavía más en un período de creciente producción visual, nos desafían a estudiar las especificidades a través de las cuales desde un vasto cuerpo de registros discursivos - que incluye entre otros los medios masivos de comunicación, softwares como Google Earth hasta las aplicaciones con juegos tan controvertidos y exitosos como Pockemon Go - se crean realidades e incluso se modelan nuestros modos de aproximarnos, experimentar e imaginar los espacios geográficos.

Quizás una de las principales aportaciones de este giro resida en abrir la disciplina al estudio de registros discursivos y prácticas que participan activamente en la creación y difusión de imágenes geográficas y como consecuencia, en la conformación de una serie de premisas que se sedimentan en nuestra memoria y operan como un sentido común geográfico. Las pu- 
blicidades, por ejemplo, exponen proposiciones acerca del mundo a audiencias diversas, apelando a imágenes grabadas en nuestra memoria visual. Todavía más, como sugiere la investigación de Martin Brückner (2006, p. 259), es precisamente en ese entramado de circulación de las imágenes, en los márgenes del ambiente textual geográfico, que ellas funcionan y refuerzan sus significaciones).

\section{Figura 2 - E1 mundo que nos proponen mirar las publicidades en diarios y revistas}

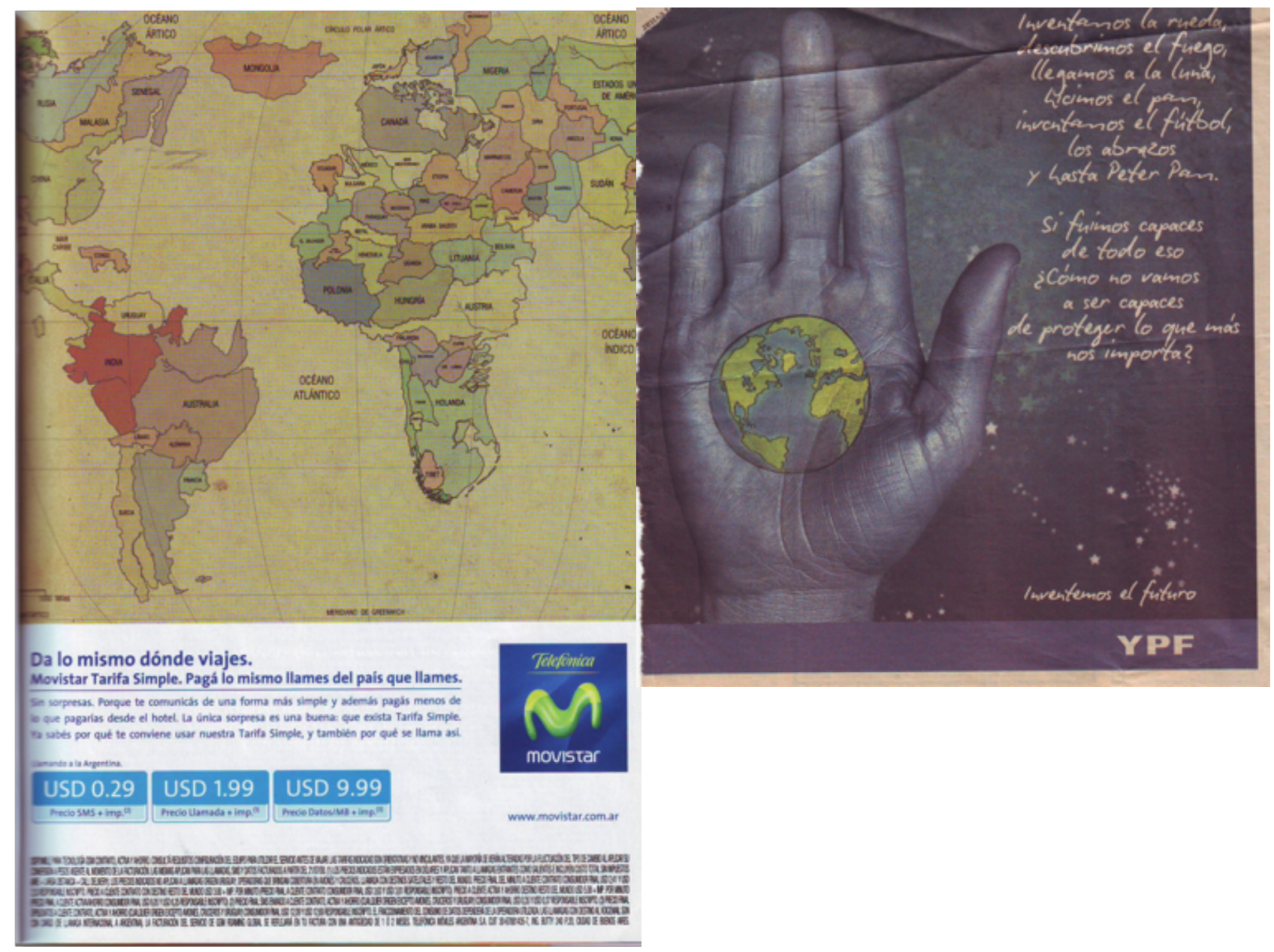

fuente: Publicidades publicadas en Revista Viva (2009) y Diario La Nación (2010).

La publicidad de una empresa de telefonía celular (Figura 2, izquierda) formula una interpretación del acceso a las comunicaciones en el mundo contemporáneo. Valiéndose de un mapamundi, una imagen grabada en nuestra memoria visual, presenta el acceso a las comunicaciones como un fenómeno homogéneo. El mapamundi actúa como referencia y a la vez desconcierta pues las siluetas cartográficas de los países han sido relocalizadas. Es precisamente esta alteración en el mapa rediseñado la que afirma visualmente la idea que el texto sintetiza: "da lo mismo donde viajes... pagá lo mismo llames del país que llames". La publicidad de la empresa estatal de petróleo de Argentina (Figura 2, derecha) recurre, en cambio, a la visión aérea con un mundo en la palma de la mano y así evoca aquellas primeras fotografías de la Tierra tomadas en las misiones de la Nasa a la Luna a fines de los años 1960 (Cosgrove, 1990, 2008b). La ilustración evoca un conjunto de imágenes que la retórica ambiental ha utilizado 
con recurrencia desde hace cuatro décadas para interpretar el planeta Tierra como un organismo vivo. La ilustración activa la memoria visual para persuadir a los potenciales clientes de las credenciales verdes de una empresa que paradójicamente utiliza recursos no renovables.

Estas geografías menores, como las ha denominado Oliveira Jr. (2009), trasvasan ampliamente las canonizadas como disciplinares, crean visibilidades y disputas en torno a lo que se visibiliza así como acerca de los modos de mirar los espacios geográficos. Nos referimos a una serie de prácticas que crean espacialidades, ya abordadas por la disciplina tales como los desplazamientos turísticos, pero también otras, como filmar o fotografiar. En este sentido, el giro visual ha estimulado el acercamiento a los trabajos de artistas que exploran visualmente temáticas de interés geográfico como por ejemplo la creciente producción de mapas artísticos, la realización de proyectos en colaboración, así como un incipiente desvanecimiento de las fronteras entre arte y ciencia en la producción geográfica.

Todavía con mayor desarrollo en el mundo anglosajón, aunque con sólidos aportes desde la geografía de América Latina, el giro visual pareciera delinear cuatro campos de investigación. Una categorización que a nuestro criterio permite entrever que en muchos casos la riqueza de estos trabajos radica precisamente en sus superposiciones y diálogos:

(i) el estatus asignado a las imágenes en las prácticas disciplinarias y por consiguiente los usos de las imágenes en la disciplina como una vía de aproximación a la configuración espacial,

(ii) los modos de mirar configurados y promovidos desde la disciplina así como aquellos que circulan más allá de los circuitos disciplinares,

(iii) la influencia de las imágenes en la configuración de nuestros modos de entender y experimentar las distintas categorías espaciales pero también en nuestra memoria geográfica y en la configuración de imaginarios geográficos y

(iv) la espacialidad del acto de mirar. Este campo de investigación, todavía menos explorado, propone analizar cómo interviene el espacio en la configuración de regímenes de visibilidad (Gomes, 2013).

Si en este tiempo se ha afirmado el consenso acerca del carácter visual de la geografía - de su tradición y sus prácticas - todavía merece mayor reflexión una serie de problemas que este giro inaugura. Nos referimos a interrogantes poco explorados (y aun no resueltos) en torno a las estrategias más apropiadas para aproximarnos por un lado, al análisis de las imágenes, desde su propio código visual, en sus pliegues y su complejidad; por otro, a los modos de mirar las imágenes geográficas producidos y puestos en circulación desde la disciplina (aunque no restringida a ella) y sobre todo, a su impacto en la configuración de memorias e imaginarios geográficos. En las secciones que siguen propongo escudriñar tres de estos campos problemáticos.

\section{Las imágenes, (en) sus códigos y pliegues}

Podríamos comenzar preguntándonos ante qué imágenes sería deseable que la geografía tome posición y las implicancias que esto supondría. Se trata de imágenes producidas como parte de un discurso científico que dan visibilidad al mundo y procuran darle un orden, a veces, una estructura. Las imágenes geográficas evidencian un esfuerzo, nada novedoso en la historia de la humanidad, de miniaturizar el mundo como una estrategia para asignarle un orden, entenderlo y en definitiva, situarnos en él. Otros registros visuales están atravesados por un esfuerzo de modelización o esquematización de una estructura o una organización. Por un lado, la imagen geográfica apela a la autoridad de la visión y, en particular, al imperio de una mirada 
totalizante: ese mundo en miniatura se despliega ante el escrutinio de nuestros ojos. Por otro lado, esa visibilización parece destinada a buscar y constatar la existencia de un orden (Cosgrove, 2008a). Estos dos elementos nodales de las imágenes geográficas funcionan y construyen su retórica desde su condición de producciones de un discurso científico. Si entendemos los aparatos de producción de las imágenes, y la ciencia es uno de ellos, como productores de verdades (Azevedo, 2014), podríamos pensar las imágenes como relatos visuales sobre lo real cuya circulación excede este entramado de origen y se extiende a otras redes de significación.

Aunque la imagen cartográfica se presenta como paradigmática de este afán de encontrar y establecer un orden, también es cierto que esta búsqueda se extiende a otros registros visuales producidos y utilizados en la disciplina. En el caso de las fotografías aéreas y las imágenes satelitales, la distancia que supone el objeto observado y el punto de captura funciona como una condición que certificaría su objetividad y que simultáneamente contribuiría en la identificación de estructuras que no veríamos de manera directa. Cabe advertir que todavía hoy, las imágenes cartográficas y las imágenes fotográficas gozan un aura de verdad irrefutable en nuestra disciplina. El carácter técnico, en el caso de los mapas y las imágenes satelitales, y el realismo, en el caso de las fotografías, las inscribe en un registro de credibilidad que borra cualquier duda o controversia, incluso en el ámbito científico. En tanto, los esquemas o los croquis proponen una visión simplificada y articulada en un modelo que les atribuye un estatus de verdad. El análisis y la reflexión de las condiciones que hacen que determinadas imágenes se tornen visibles en nuestra disciplina y se les asigne atributos particulares redundará, sin duda, en una mayor solidez teórica y metodológica.

La reciente difusión de softwares amigables como Google Earth no solo ha contribuido a una creciente familiarización de este registro visual, sino que también ha desvanecido del imaginario las dimensiones sensoriales, sintáctica y semántica que comprende su producción, tratamiento e interpretación que, como lo destaca Ricardo Castillo (2009), tienen incidencia directa en la imagen que vemos y en lo que podemos mirar a través de ella. La producción de toda imagen entraña tareas de orden conceptual, técnico y estético que también son de orden político. Tal vez como una consecuencia no deseada de otros giros o de la autonomización de la cartografía como campo de conocimiento (Lois, 2014), en la práctica académica y profesional se tiende a delegar la producción de imágenes a técnicos y a renunciar a ser parte de decisiones que afectan qué y cómo miramos. Si todavía queremos producir imágenes que, lejos de pretender la exposición de verdades indiscutibles, inquieten y provoquen el pensamiento, es necesario que los geógrafos nos involucremos en esas tareas y seamos conscientes de cada una de las decisiones que tomamos, con las inclusiones y exclusiones que ellas implican.

El giro visual también supone entender que las imágenes constituyen un orden de conocimiento con su propia lógica. Dicho de otro modo, implica aceptar que lo visual no se puede explicar por completo mediante el modelo textual (Mirzoeff, 2003) pues no tiene las mismas reglas de otros lenguajes en los cuales hemos sido alfabetizados. Además de la complejidad propia de otro lenguaje, deberíamos señalar que cada registro visual - películas, mapas, fotografías, gráficos, esquemas, etcétera - tiene características particulares y esto complejiza aún más el escenario de investigación. Se imponen una serie de interrogantes de método: ¿Cómo organizar y entender este vasto cuerpo visual? ¿Cómo trabajar las características propias de la imagen: su arquitectura visual, su soporte, las tecnologías que le confieren materialidad? El andamiaje teórico-metodológico de la disciplina se vuelve insuficiente para trabajar las imágenes en su propia "gramática" y a la vez como parte de un entramado social y cultural. El trabajo con las imágenes exige recurrir a un andamiaje teórico- 
-metodológico de la semiología, de la interpretación composicional, del análisis del discurso y de los estudios visuales (Rose, 2012). En otras palabras, para entender las imágenes desde su código visual precisamos muñirnos de un arsenal que roza lo ecléctico y lo creativo.

Asimismo, este giro nos convoca a re-pensar la formación de los geógrafos en relación a la producción, análisis e interpretación de un universo más vasto de imágenes (Thornes, 2004). Sólo podremos analizar, interpretar y producir imágenes poderosas si nos entrenamos a pensar y expresarnos visualmente (Arnheim, 1997). Entre otras tareas cognitivas, pensar visualmente permite establecer correlaciones, encontrar regularidades y analogías, identificar particularidades y sobre todo provocar nuevos interrogantes como lo evidencia la historia de la ciencia, en general, y la historia de la observación científica, en particular Barrow (2009) y Daston y Lunbeck (2011).

\section{Regímenes de visualidad y espacialidad}

Mirar es un acto personal que está moldeado y/o mediado por un conjunto de circunstancias. En efecto, mirar es una experiencia hendida en el tiempo (Didí-Huberman, 2006) y situada en un lugar concreto. Del mismo modo que algunos objetos técnicos han hecho visibles objetos o procesos que de manera directa no podríamos ver, existe un conjunto de reglas que actúan como lentes o filtros en el acto de mirar. El historiador Martin Jay (1988) denominó régimen de visualidad o régimen escópico a ese conjunto de reglas que, ligadas a las prácticas, valores y otros aspectos culturales, históricos y epistémicos de una sociedad, habilitan qué se ve y, a su vez, qué se considera digno de atención. La función que tienen estas reglas es ordenar, delimitar qué, cómo y cuándo se debe mirar. En definitiva, los regímenes escópicos configuran el campo de visibilidad y definen la verosimilitud de aquello que estamos viendo: creemos en aquello que estamos habilitados a ver.

Si asumimos que la imagen no es estable, en parte esta inestabilidad se explica en la diversidad de formas que toma la experiencia visual: no existiría un único régimen de visualidad, sino que podría coexistir más de uno e incluso entrar en tensión y disputa. Un nivel de análisis examina la participación de la geografía en la construcción y circulación de determinados modelos históricos de visión. En otras palabras, ¿Qué regímenes de visualidad son promovidos desde la geografía? ¿Qué reglas del "buen" mirar son producidas y puestas en circulación desde la disciplina y sus prácticas? ¿Cómo han participado las imágenes en la organización visual del conocimiento geográfico?

La temprana inclusión de la geografía en el curriculum escolar, en un contexto de expansión de la escolarización, la consolidó como una de las prácticas que, con fuerza y efectividad, ha configurado reglas del mirar. Varias investigaciones han examinado la participación de la geografía escolar en la construcción de un modo de mirar nacionalista particularmente evidenciada en el caso de Argentina en la permanencia de algunos contenidos curriculares concernientes a la organización territorial, la nacionalización de los paisajes y la interpretación de una grandeza nacional como resultado de las potencialidades naturales del territorio. Me interesa centrarme aquí en la coexistencia de tres regímenes de visualidad identificados a través del examen de libros escolares de tres períodos históricos en Argentina. Se trata de tres modos de mirar que construyen la disciplina escolar y se ponen en juego ante un mismo registro visual a través de un conjunto de claves visuales y textuales (Hollman; Lois, 2015). El mirar turístico se fomenta a través de fotografías que exponen vistas panorámicas, muy similares a las que podríamos encontrar en álbumes de tarjetas postales o de fotografías de viajeros. La visión pa- 
norámica ofrece un amplio horizonte visual y destaca los rasgos más prominentes de las formas geográficas que se refuerza en la conformación de series de paisajes organizados a modo de itinerario turístico y de epígrafes con adjetivos que destacan su condición de bellos, pintorescos o típicos y los canonizan como postales de Argentina. El mirar científico también se vale de la captura panorámica y aérea que se refuerza con textos centrados en la identificación de los elementos visibles, en la descripción de su aspecto, su medición, clasificación y categorización, excluyendo toda apreciación estética. Asimismo, utiliza capturas visuales de proximidad: la cámara permite hacer un acercamiento y así ofrecer detalles que podrían resultar imperceptibles de manera directa para el ojo. El mirar periodístico se construye a través de fotografías que confirman la veracidad de la información y buscan provocar cierta conmoción: documentan eventos al capturarlos en el momento preciso de su ocurrencia. Estos tres modos de mirar son coexistentes y moldean oportunamente el campo de visibilidad de la geografía escolar.

El desprendimiento de los registros visuales de los contextos primarios de producción y circulación traza un segundo nivel de análisis: la intervención de la espacialidad en los modos de mirar. El interrogante que se impone es si esta imbricación de los contextos delinea rasuras en los regímenes de visibilidad o por el contrario, refuerza la efectividad del sentido primario de la imagen y su devenir en sentido común. Para aventurar cómo incide la espacialidad en nuestro encuentro con las imágenes y en los modos de mirarlas me valdré de una corriente del arte que ha tomado fuerza desde los años 1990. Se trata de las instalaciones o intervenciones artísticas, entendiendo por ellas a los montajes de las imágenes en los cuales el lugar toma la escena y forma parte de la composición artística.

La Figura 3 presenta una selección de fotografías que tomé en una de las salas de la exposición Relato de una negociación, de Francis Alÿs (Museo de Arte Latinoamericano de Buenos Aires, 11/2015 al 2/2016). La fotografía superior derecha muestra un mapa expuesto en una mesa ubicada en el espacio central de la sala. Sobre esa mesa/mapa se disponen dos tenedores que, en un punto de equilibrio inestable, unen a modo de puente el Estrecho de Gibraltar. Con este artificio se problematiza la proximidad entre Europa y África dibujada en el mapa ya no como una distancia, sino como una frontera en toda su arbitrariedad e inestabilidad. El mapa/mesa dialoga con una instalación que recrea en la sala una acción realizada por el artista in situ en la cual, desde ambos lados del Estrecho de Gibraltar, dos grupos de niños intentaron formar un puente flotante, cada uno llevando los prototipos de barcos. Una hilera de pequeños barcos hechos con sandalias llegan hasta un espejo que nos devuelve nuestra propia imagen y así nos sitúa en esa travesía y en el interrogante que plantea el artista: "Si una fila de niños sale de Europa hacia Marruecos, y una fila de niños sale de África hacia España, ¿se encontrarán las dos filas en la quimera del horizonte?" (Alÿs, 2015, p. 135). El mapa/mesa se vuelve a trazar en pequeños cuadros, montados en distintas paredes de la misma sala, con cuerpos que están atravesando las siluetas cartográficas y que refuerzan la idea de separación y desplazamiento. El artista dirá: "El mar será representando como la fuerza que siempre arrastra a los niños de vuelta a la orilla; los niños serán los héroes valientes que intentan engañar al destino [...]" (Alÿs, 2015, p. 143). Como parte una colección de imágenes este montaje escapa de los clichés visuales expuestos en los medios masivos de comunicación y ofrece una mirada política y poética de la migración así como de las líneas/fronteras. 
En este lugar, el mapa/mesa supone un observador que deambula con su propio ritmo, que mira esta imagen como parte de una serie cuidadosamente seleccionada para estimular diálogos entre ellas, que está dispuesto a sorprenderse/ extrañarse ante estos objetos dislocados en su contenido, sus usos y sus finalidades. Dicho de otro modo, el uso de los mapas en los contextos artísticos - ya no solo por su contenido - nos fuerza a mirar de otro modo esa imagen conocida que se vuelve extraña y hasta puede lograr incomodarnos. Si los mapas expuestos en una pared escolar todavía suponen un observador que cree saber precisamente lo que puede encontrar en esa imagen, el encuentro con este y otros registros visuales en una instalación habilita a quien mira a tener más interrogantes que respuestas, más incertidumbres que certezas. Las instalaciones artísticas nos muestran que son precisamente estas incertezas, provocadas desde la imagen y su espacialidad, las que ofrecen posibilidades de perforaciones en los regimenes de visualidad.

\section{Figura 3 - Mirar mapas que forman parte de una instalación}
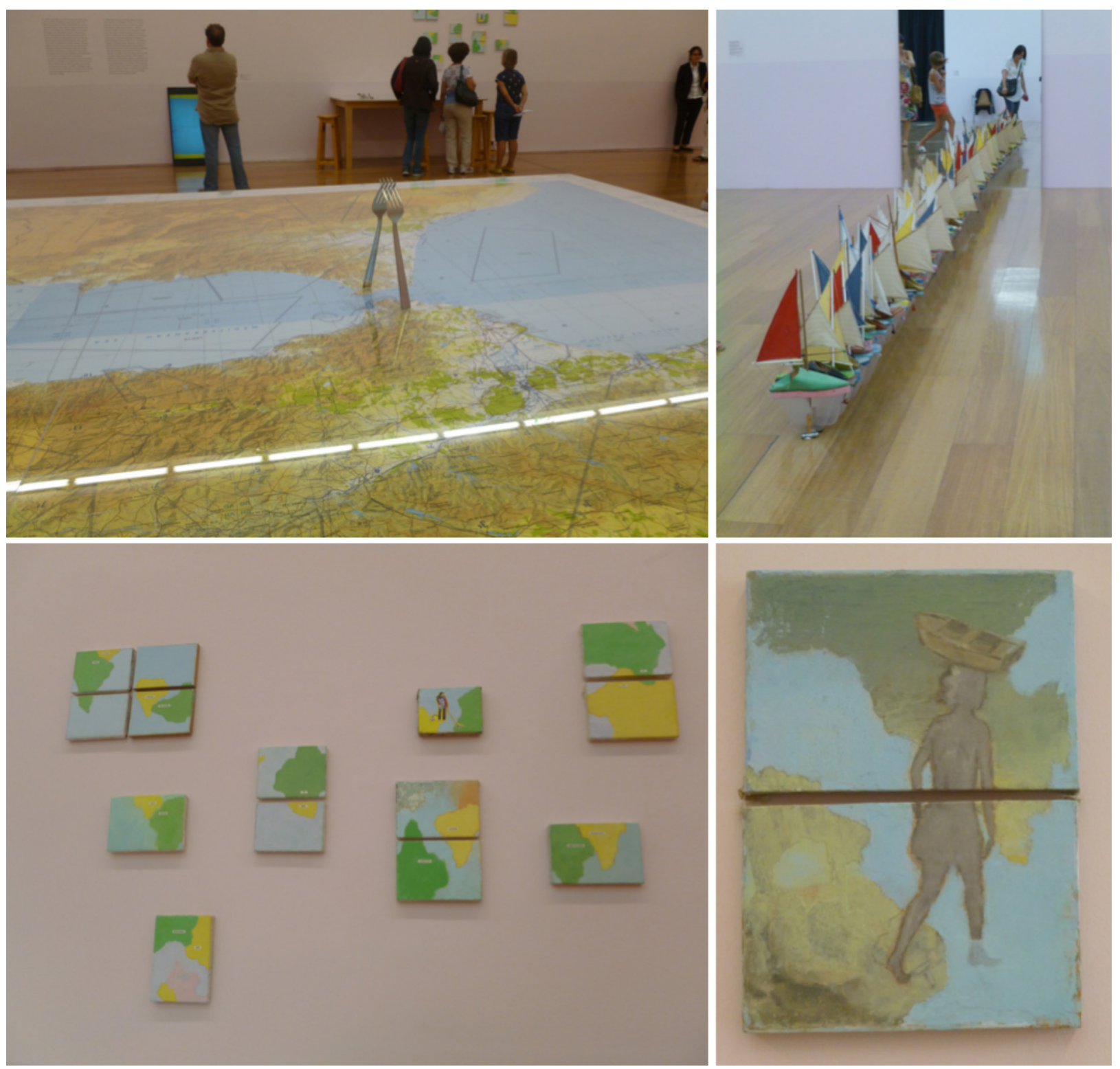

fuente: Fotografías de la autora de la instalación titulada "No cruzarás el río antes de llegar al puente", que formó parte de la exposición del artista belga-mexicano Francis Alÿs Relato de una negociación, Museo de Arte Latinoamericano de Buenos Aires (Malba), nov. 2015 feb. 2016. 


\section{Los efectos de las imágenes en nuestra experiencia espacial}

Entender las imágenes como registros gráficos que ofrecen proposiciones sobre el mundo abre otro campo de indagación por demás interesante: los efectos de las imágenes en nuestras experiencias espaciales y las formas a través de las cuales las pensamos, elaboramos, comprendemos y asimilamos. En otras palabras, si asumimos que las imágenes median gran parte de nuestras experiencias espaciales deberíamos preguntarnos acerca de sus efectos en los modos percibir, recordar, posicionarnos, actuar e imaginar geográficamente.

La incidencia de las imágenes en diversas facultades cognitivas que se ponen en juego en nuestras experiencias espaciales ha sido generalmente analizada partiendo del supuesto que la eficacia de una imagen puede inferirse a partir de su índice de repetición y de los modos de circulación y exhibición (Lois, 2014, p. 246). Sin duda, la relación existente entre la temprana y reiterada exposición de determinadas imágenes, particularmente el mapa-logotipo (Anderson, 2008), y la conformación/ estabilización de memorias nacionales es uno de los procesos más destacados en la literatura tomando como corpus de análisis básicamente los libros escolares, pero también a través de otros registros discursivos de circulación incluso más amplia como los sellos postales, las tarjetas postales o las publicidades. Christian Jacob (2006) discute una multiplicidad de estrategias destinadas a "aprender el mapa", destacando la fuerza que adquiere en la sedimentación del logotipo territorial del Estado el mapa pegado en las aulas de las escuelas primarias. La Figura 4, una fotografía tomada en la década de 1940 en el patio de una escuela de Argentina, presenta un grupo de niñas trazando de las formas del territorio como una actividad colectiva en la que se despliegan habilidades manuales que rozan lo lúdico. A pesar del orden que expone la escena y la presencia de una maestra que pareciera estar dirigiendo la actividad, dibujar el logotipo territorial a modo de juego en el patio, un lugar de recreación, sugiere su omnipresencia en el ámbito escolar.

Ahora bien, poco sabemos sobre cómo se han asimilado y decantado estas imágenes en los sujetos a través "una serie de premisas sencillas sobre las formas y las propiedades del territorio" (Lois, 2014, p. 246). Sabemos que la imagen tiene un lugar constitutivo en la memoria: "nuestra memoria sólo está hecha de fotografías" (Dubois, 2008, p. 276) y que incluso "recordar es, cada vez más, no tanto recordar una historia sino ser capaz de evocar una imagen" (Sontag, 2003, p. 104). La memoria podría entenderse, entonces, como un acervo de conocimientos, experiencias vividas y conceptos visuales (Arnheim, 1997) que, con mayor o menor grado de claridad y complejidad y nos permiten reconocer lo que vemos y atribuirle sentido. Al menos dos características definirían la inscripción de las imágenes, por un tiempo más o menos variable, en lugares de nuestra memoria, en permanente tensión entre el acto de recordar y el acto de olvidar: su excepcionalidad y el impacto emocional-afectivo que provocan (Oliveira Jr., 2013). 
Figura 4 - Dibujar para sedimentar las imágenes de la nación - Escuela Sarmiento, Tucumán, circa 1930

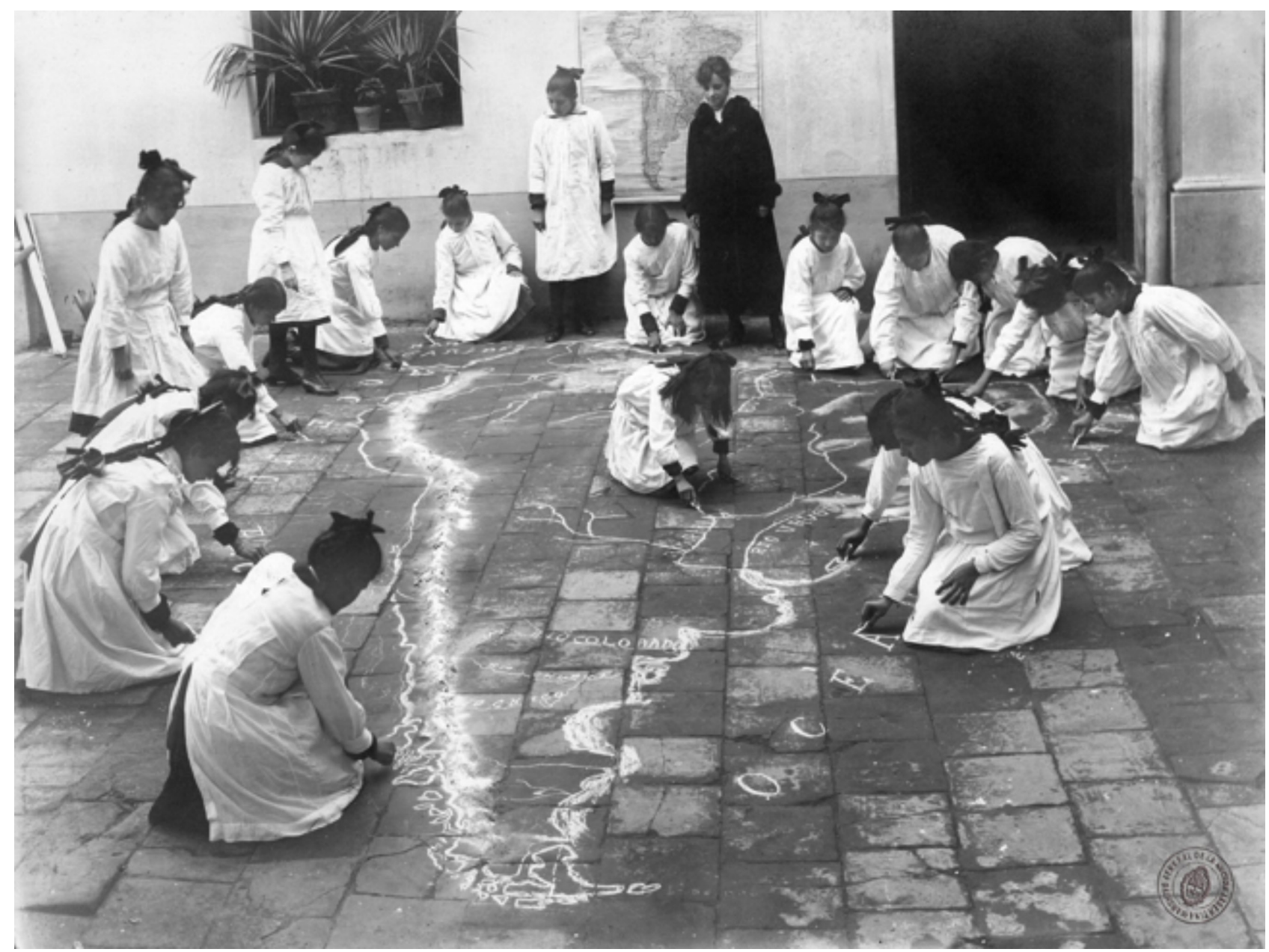

fuente: Archivo General de la Nación.

Desde el encuadre de la Psicología Cognitiva, Rudolf Arnheim explica que si bien la memoria no constituiría un todo integrado, estaría configurada por series de conceptos agrupados por afinidad temática, similitud, asociación tiempo-espacio, contexto temporal o espacial de creación. Así cuando nuestros ojos se encuentran con una imagen reconocemos en ellas determinados elementos visuales que nuestra memoria identifica al evocar otras imágenes que hemos visto (y continuamos viendo) en diarios, revistas, libros, publicidades, entre tantos otros discursos visuales. Todavía más: "la memoria vincula razón y emoción, remite a los sentidos de la experiencia vivida y a la capacidad de lidiar con una variedad de tiempos y espacios del sujeto" (Rocha; Martins, 2012, p. 54). La memoria visual entonces activaría un conjunto de identificaciones y/o recordaciones que de algún modo provocan un grado de movilización subjetiva.

Los mapas se presentan como un punto de partida con potencial analítico, todavía poco aprovechado, para aprehender esa memoria visual que funciona como sentido común y delinea nuestras experiencias espaciales (Seemann, 2003; García Álvarez, 2009). La indagación de Carla Lois (2014) a partir de una encuesta visual de la que participó un universo amplio y diverso de personas constituye una aproximación valiosa para entender los mecanismos de decantación del mapa-logotipo y su devenir en sentido común. De modo análogo explora- 
mos la participación de otras imágenes, particularmente las fotografías, en la conformación de una memoria ambiental y sus efectos en los modos de entender, conceptualizar e imaginar la naturaleza y sus transformaciones (Hollman, 2014). En el corpus de mapas mentales se inscriben de una u otra manera imágenes ambientales con diferentes grados de decantación: en algunos casos la imagen aparece recreada con una palabra, mientras que en otros fue siendo metamorfoseada hasta llegar a un concepto que expresa un mayor grado de sofisticación en el ordenamiento del material visual. La identificación de las imágenes que fueron decantando y constituyendo la memoria ambiental sugiere que la apelación más directa al registro sensorial y afectivo configura la superficie privilegiada de inscripción, una superficie que se vuelve muy difícil de borrar inclusive cuando algunas de estas temáticas fueron perdido el protagonismo que alguna vez les dieron las organizaciones ambientales o los medios de comunicación. Pero también este proceso sugiere que la decantación y sedimentación de estas imágenes en nuestra memoria se produce cuando ellas circulan en distintos registros discursivos y soportes y logran conformar un verdadero entramado visual que entrena y configura, tomando la expresión de Berger (2005), ciertos modos de mirar lo ambiental.

Indagar los efectos de las imágenes también invita a pensar en la imaginación entendida como la apertura a posibilidades que aún no han sido establecidas (Didí-Huberman, 2013). No solo miramos las imágenes y las inscribimos en los lugares de nuestra memoria; también somos capaces de crear imágenes, es decir, tenemos la posibilidad de activar procesos creativos con (diversas y complejas) implicancias en las geografías materiales (Zusman, 2013, p. 59). Si volvemos al estudio exploratorio ya señalado, algunos de los mapas ambientales exponen con anticipación temas que, en el momento que fue realizado el ejercicio visual, todavía no habían logrado posicionarse en la agenda ambiental nacional. Es el caso de la explotación no convencional de petróleo y gas, un tema que se presenta visualmente en algunos mapas anticipando lo que, seis meses después de realizado el ejercicio visual, se convertiría en el nuevo conflicto ambiental de la Argentina. Esto nos indicaría que las imágenes podrían funcionar como inscripciones de la imaginación y de este modo, su análisis nos permitiría identificar y entender procesos en devenir así como sus efectos en tanto acontecimientos de lo real.

\section{Cerrar los ojos para volver a mirar}

Didí-Huberman apunta que "una imagen bien mirada sería una imagen que logra desconcertar, después renovar nuestro lenguaje y, por lo tanto, nuestro pensamiento" (2012, p. 204). Las imágenes asumen una centralidad desde lo poético y desde lo político que no deberíamos relegar para inquietar nuestras certezas y provocar nuevas preguntas a temáticas de la tradición disciplinar y a otras que la contemporaneidad traza en las agendas de investigación. La identificación, el análisis y la problematización de los modos de mirar producidos y promovidos desde la disciplina, acaso una de las novedades más interesantes de este giro, inscriben el reconocimiento de la subjetividad y de la multiplicidad de aconteceres que los regímenes visu-

ales sistemáticamente nos han impedido mirar. El giro visual, sin duda, nos invita a interrogar si las imágenes que producimos, estudiamos y ofrecemos desde la disciplina tienen la potencialidad de afectar nuestras experiencias espaciales y de entrever procesos que todavía se nos escapan en su aprehensión. 


\section{Bibliografía}

ALŸS, F. Relato de una negociación: una investigación sobre las actividades paralelas del performance y la pintura. Buenos Aires: Malba, 2015.

ANDERMANN, J. The Optic of the State: Visuality and power in Argentina and Brazil. Pittsburgh: University of Pittsburgh Press, 2007.

ANDERSON, B. Comunidades imaginadas. Sao Paulo: Companhia das Letras, 2008.

ARNHEIM, R. Visual Thinking. Berkeley: The University of California Press, 1997.

AZEVEDO, A. F. Cultura visual: as potencialidades da imagem na formação do imaginário. Revista Geografares, Vitória, p. 7-21, jan./ago. 2014.

BARROW, J. Imágenes del cosmos: las mejores imágenes de la historia de la ciencia. Barcelona: Paidós, 2009.

BERGER, J. Mirar. Buenos Aires: Ediciones de la Flor, 2005.

BRÜCKNER, M. The Geographic Revolution in Early America: Maps, Literacy, E National Identity. Virginia: The University of North Carolina Press, 2006.

CASTILLO, R. A imagem de satélite: do técnico ao político na construção do espaço geográfico. Pro-Posições, Campinas, v. 20, n. 3, p. 61-70, 2009. (Dossiê A Educação pelas Imagens e suas Geografias.)

COSGROVE, D. Geography \& Vision. Seeing, imagining and representing the world. London: I. B. Tauris, 2008a.

. Images and imagination in 20th-century environmentalism: From the Sierras to the Poles. Environment and Planning A, v. 40, n. 8, p. 1862-1880, 2008b.

Observando la naturaleza: el paisaje y el sentido europeo de la vista. Boletín de la Asociación de Geógrafos Españoles, Madrid, n. 34, p. 63-90, 2002.

Apollo's eye. A cartographic Genealogy of the Earth in the Western Imagination.

Baltimore: The Johns Hopkins University Press, 2001.

Environmental and action: thought and post-modern. Transactions of the Institute of British Geographers, v. 15, n. 3, p. 344-358, 1990.

; FOX, W. Photography and Flight. London: Reaktion Book, 2010.

CRANG, M. The Hair in the Gate: Visuality and Geographical Knowledge. Antipode, v. 35, n. 2, p. 238-243, 2003.

CRANG, P. Cultural turns and the (re)constitution of Economic Geography. In: LEE, R.; WILLS, J. (Ed.). Geographies of economies. London: Arnold, 1997.

DANIELS, S. Fields of Vision. Landscape imagery \& national identity in England \& The United States. Princeton: Princeton University Press, 1993.

DASTON, L.; LUNBECK, E. Histories of scientific observation. Chicago: The University of Chicago Press, 2011. 
DIDÍ-HUBERMAN, G. Atlas ou a Gaia Ciência inquieta. Lisboa: KKYM+EAUM, 2013. Quando as imagens tocam o real. Pós, Belo Horizonte, v. 2, n. 4, p. 204-219, nov. 2012.

. Lo que vemos, lo que nos mira. Buenos Aires: Manantial, 2006.

DIKOVITSKAYA, M. An interview with Thomas Conley. In: Visual Culture: The Study of the Visual after the Cultural Turn. Cambridge: The MIT Press, 2006.

DRIVER, F. Sobre a geografia como uma disciplina visual. Espaço e Cultura, UERJ: Rio de Janeiro, n. 33, p. 207-212, jan./jun. 2013.

DUBBINI, R. Geography of the Gaze: Urban and Rural Vision in Early Modern Europe. London: The University of Chicago Press, 2002.

DUBOIS, P. El acto fotográfico. Buenos Aires: La Marca, 2008.

DYM, J.; OFFEN, K. Mapping Latin America: A cartographic reader. London: The University of Chicago Press, 2012.

FIELL, C.; RYAN, J. Memories of a Lost World: Travels through the Magic Lantern. China: Fiell, 2011.

FONSECA, F; OLIVA, J. Cartografia. Sao Paulo: Melhoramentos, 2013.

FRANKLIN, S. Footprint our Landscape in Flux. London: Thames \& Hudson, 2008.

GARCÍA ÁLVAREZ, J. Lugares, paisajes y políticas de memoria. Boletín de la Asociación de Geógrafos Españoles, n. 51, p. 175-202, 2009.

GOMES, P. O lugar do olhar. Elementos para uma geografia da visibilidade. Rio de Janeiro: Bertrand Brasil, 2013.

HAWKINS, S. National Geographic's Romance in Ruins: From the Catastrophic Sublime to Camp. In: American Iconographic: National Geographic, Global Culture, and Visual Imagination. Charlottesville: The University of Virginia Press, 2010. p. 172-209.

HERMANOS DE LAS ESCUELAS CRISTIANAS. Geografía: Libro Primero para la Enseñanza Primaria. 10. ed. ilustr. Buenos Aires: Librería de José Moly, [1910?].

HOLLMAN, V. Glass lantern slides and visual instruction for school teachers in early twentieth-century Argentina. Early Popular Visual Culture, London, n. 14, p. 1-15, Apr. 2016. . Mapas, imaginarios y memoria ambiental en la Argentina. Geografares, Vitória, p. 96117, jan./ago. 2014. (Edição Especial.)

; LOIS, C. Geo-grafías: imágenes e instrucción visual en la geografía escolar. Buenos Aires: Paidós, 2015.

JACOB, C. The sovereign map: theoretical approaches in cartography throughout history. Chicago: The University of Chicago Press, 2006.

JAY, M. Scopic regimes of modernity. In: FOSTER, H. (Ed.). Vision and visuality. Seattle: Bay Press, 1988. 
LE SILENCE (SOKOUT). Dirección: Mhoser Makhamalbf. Intérpretes: Tahmineh Normatova, Nadereh Abdelahyeva, Araz M. Shirmohamadi, Hakem Ghassem, Golbibi Ziadolahyeva. Guión: Mhoser Makhamalbf. Irán, Francia, Tayikistán, 1998. 1 rollo de película, 76 min., son., color.

LINDÓN, A., HIERNAUX, D. Geografías de lo imaginario. Barcelona/México: Anthropos/ Universidad Autónoma Metropolitana, 2012.

LOIS, C. Mapas para la nación: episodios en la historia de la cartografía Argentina. Buenos Aires: Biblos, 2014.

. Sketch Maps and the Geographical Visual Tradition in Twentieth-Century School Texts. Mapline, n. 121, p. 1-4, Fall 2013.

; HOLLMAN, V. Geografía y cultura visual: los usos de las imágenes en las reflexiones sobre el espacio. Rosario: Prohistoria, 2013.

LUTZ, C.; COLLINS, J. Reading National Geographic. Chicago: The University of Chicago Press, 1993.

MATLESS, D. Gestures around the Visual. Antipode, v. 35 n. 2, p. 222-226, 2003.

MIGLIORIN, C. Inevitavelmente cinema: educação, política e mafuá. Rio de Janeiro: Beco do Azougue, 2015.

MIRZOEFF, N. Una introducción a la cultura visual. Barcelona: Paidós, 2003.

NOVAES, A. R. A iconografia das drogas ilícitas na imprensa (1975-2002). Dissertação (Mestrado em Geografia) - Universidade Federal do Rio de Janeiro, Rio de Janeiro, 2005.

OLIVEIRA JR., W. Corpos e sons - locais e imagens: o Ad Herennium sob as Vilas Volantes. In: CAZETTA, V.; OLIVEIRA JR., W. (Org.). Grafias do espaço: imagens da educação geográfica contemporânea. Campinas: Alínea, 2013. p. 167-192.

Grafar o espaço, educar os olhos: rumo a geografias menores. Pro-Posições, v. 20, n. 3, p. 17-28, set./dez. 2009.

PLOSZAJSKA, T. Geographical Education, Empire and Citizenship: Geographical Teaching and Learning in English Schools, 1870-1994. Liverpool: Liverpool Hope University College, 1999. v. 35. (Historical Geography Research.)

P○C○CK. D. Sight and knowledge. Transactions of the Institute of British Geographers, v. 6 , n. 4, p. 385-393, 1981.

POOLE, R. Earthrise: How man first saw the Earth. London: Yale University Press, 2008.

ROCHA, H.; MARTINS, M. C. Escola e cultura: sobre história, narrativas e cultura escolar. In: ___ (Org.). Educação e cultura: formação de professores e práticas educacionais. Campinas: Alínea, 2012. p. 43-60.

ROSE, G. Sobre a necessidade de se perguntar de que forma, exatamente, a geografia é "visual"? Espaço e Cultura, Rio de Janeiro: UERJ, n. 33, p. 197-206, jan./jun. 2013. 
- Visual methodologies: An introduction to Researching with Visual Materials. London: Rutledge, 2012.

RYAN, J. R. Photography and exploration. London: Reaktion, 2013.

On visual instruction. In: SCHWARTZ V. R.; PRZYBLYSKI, J. M. (Ed.). The Nineteenth-Century Visual Culture Reader. London: Routledge, 2004. p. 145-150.

Who's Afraid of Visual Culture? Antipode, v. 35, n. 2, p. 232-237, 2003.

SCHULTEN, S. The geographical imagination in America, 1880-1950. Chicago/London: The University of Chicago Press, 2002.

SCHWARTZ, J.; RYAN, J. Picturing place: Photography and the Geographical Imagination. London: I. B. Tauris, 2006.

SEEMANN, J. O espaço da memória e a memória do espaço: algumas reflexões sobre a visão espacial. Revista da Casa da Geografia Sobral, n. 4/5, p. 43-53, 2003.

SONTAG, S. Ante el dolor de los demás. Buenos Aires: Alfaguara, 2003.

SZIR, S. Infancia y cultura visual: Los periódicos ilustrados para niños (1880-1910). Buenos Aires: Miño y Dávila, 2006.

THORNES, J. E. The Visual Turn and Geography (Response to Rose 2003 Intervention). Antipode, v. 36, n. 5, p. 787-794, 2004.

TOLIA-KELLY, D. P. The geographies of cultural geography II: Visual culture. Progress in Human Geography, v. 36, n. 1, p. 135-142, 2011.

TUAN, Y. Sight and pictures. Geographical Review, n. 69, p. 413-422, 1979.

YUSOFF, K.; GABRYS, J. Cultural geographies in practice Time lapses: Robert Smithson's mobile landscapes. Cultural Geographies, n. 32, p. 444-451, 2006.

WOOD, D. Everything sings. Maps for a narrative atlas. Los Angeles: Siglio, 2010.

; FELS, J. The nature of maps: Cartographic constructions of the Natural Word. Chicago: The University of Chicago Press, 2008.

ZUSMAN, P. La geografía histórica, la imaginación y los imaginarios geográficos. Revista de Geografia Norte Grande, n. 54, p. 51-66, 2013. 